\title{
Understanding Different Cultural Patterns or Orientations Between East and West*
}

\author{
Liu Qingxue ** \\ Shijiazhuang Mechanical Engineering College \\ Hebei, CHINA \\ liuqx1952@yahoo.com.cn
}

\begin{abstract}
Rudyard Kipling says in the Ballad of East and West: "East is East, and West is West; and never the twain shall meet." Yet, he never expected that with the technological development in transportation and communication, the Westerners and Easterners that have quite different cultures respectively would meet so frequently nowadays in international settings. However, in a sense, Kipling is absolutely correct in that people with different cultural patterns (including beliefs, values, attitudes, norms, customs, and material aspects), especially those from East and West, do encounter communication difficulties, breakdowns, misunderstandings and even conflicts and confrontations just because they fail to understand each other in their intercultural communication.

The study of intercultural communication is not something new. However, the perspective from which the author probes into the problematic interaction between Easterners and Westerners is something different. In the paper, the author compares some major cultural patterns: high-context communication vs. low-context communication, individualism vs. collectivism, equality vs. hierarchy, and assertiveness vs. interpersonal harmony. Each of these cultural patterns is defined by examples, two opposite patterns are contrasted, and then potential problems are presented, thus making quite obvious the differences between East and West and their possible consequences in the intercultural communication. Understanding these cultural patterns or orientations which underlie most common behavior of the Easterners and Westerners helps us to see beneath the surface to find out why people from East and West act as they do. This discovery may lead us to appreciate the rich diversity and genius that exist in different parts of the globe, avoid potential intercultural problems and become successful communicators in the interaction between East and West.
\end{abstract}

\section{Introduction}

In studying the subject of intercultural communication, the first question we raise might be "What is culture?". As early as 1952, Kroeber and Kluckhohn listed 164 definitions of culture that they found in the anthropology literature [1]. And, of course, many new definitions have appeared since.

\footnotetext{
* The author is very grateful to Prof. dr. hab. Wanda Krzemińska, Institute of Linguistics, Adam Mickiewicz University, Poznań, Poland, for her helpful suggestions and professional guidance. For any controversial viewpoints and mistakes in the paper, the author himself is responsible.

** The author, Professor of English, Shijiazhuang Mechanical Engineering College, Hebei, the People's Republic of China, is now visiting the Institute of Linguistics, Adam Mickiewicz University, Poznań, Poland.
} 
According to Bates and Plog, "Culture is a system of shared beliefs, values, customs, behaviors, and artifacts that the members of a society use to cope with their world and with one another, and that are transmitted from generation to generation through learning"[2]. This definition includes most of the major aspects of culture on which scholars currently agree: patterns of thought (shared meanings that the members of a society attach to various phenomena, natural and intellectual, including religion and ideologies), patterns of behavior, artifacts (tools, pottery, houses, machines, works of art), and the culturally transmitted skills and techniques used to make the artifacts.

It is generally assumed that "belief systems are significant to the study of intercultural communication because they are at the core of our thoughts and actions. They are our conviction in the truth of something. They tell us how the world operates"[3]. Values are, according to Rokeach, "a learned organization of rules for making choices and for resolving conflicts" [4]. These "rules" and guideposts are normative and teach us what is useful, good, right, wrong, what to strive for, how to live our life, and even what to die for.

Although each of us has a unique set of individual values, there are also values which tend to spread into every part of a culture. These are called cultural values. Cultural values are derived from the larger philosophical issues that are part of culture's social surroundings. Cultural values are transmitted by a variety of sources - family, media, school, church, state, and so on - and therefore tend to be broadly based, enduring, and relatively stable. Most important, as is the case with our beliefs, cultural values guide both perception and communication. That is, our values get translated into action. An understanding of cultural values helps us appreciate the behavior of other people.

Important as cultural beliefs and values are to our world views or ideologies, cultures are extremely complex and consist of numerous interrelated cultural orientations besides beliefs and values, including attitudes, norms, and material aspects. A useful umbrella term which enables us to talk about these orientations collectively rather than separately is cultural patterns, which refer to both the conditions that contribute to the way in which people perceive and think about the world, and the manner in which they live in the world.

In the following sections we will discuss four major pairs of opposite or quite different cultural patterns or orientations, which lie in the deep structure of Western and Eastern cultures. Knowing these different cultural patterns will help us gain insight into the cultural-specific behavior of our Western or Eastern interacting counterparts.

Before we talk about different cultural patterns or orientations between East and West, there are several points which need to be made clear. First, since this topic is broadly-dimensioned, this paper is unable to cover all the aspects of this field; instead, it can only concentrate on major aspects. Second, as there are so many countries both in the eastern and western parts of the globe, and each country has its own peculiar culture and co-cultures, when we talk about Eastern culture or Western culture as a whole, we can only focus on the major views, values, cultural patterns or orientations shared by the most influential group of people in the most influential countries or cultures in that part of the world. And likewise, when we speak of a culture, we are actually speaking of the dominant and mainstream culture, not its subcultures or co-cultures. Third, even within one cultural pattern or orientation, there are varieties of individual behavior. So what we can do is only to choose those which are most manifest during intercultural communication. Finally, since the author of this paper is from China, there might be manifestations of native cultural influences, stereotypes, bias and even ethnocentrism in the paper, although that's also what the author strives to avoid.

\section{High-context Versus Low-context Communication}

Hall offers us an effective means of examining cultural similarities and differences in both perception and communication. He categorizes cultures as being either high or low context, depending on the degree to which meaning comes from the settings or from the words being exchanged [5]. Hall and Hall define context as "the information that surrounds an event; it is inextricably bound up with the meaning of the event" [6]. They maintain that although all cultures contain some characteristics of both high and low variables, most can be placed along a scale 
showing their ranking on this particular dimension (see Figure 1). The Halls define these two terms in the following way:

A high context $(\mathrm{HC})$ communication or message is one in which most of the information is already in the person, while very little is in the coded, explicitly transmitted part of the message. A low context (LC) communication is just the opposite; i.e., the mass of the information is vested in the explicit code [7].

\section{High-Context Cultures}

\begin{tabular}{c}
\hline Japanese \\
Chinese \\
Korean \\
African American \\
Native American \\
Arab \\
Greek \\
Latin \\
Italian \\
English \\
French \\
American \\
Scandinavian \\
German \\
German-Swiss \\
\hline Lower-Context Cultures
\end{tabular}

\section{Figure 1. Cultures Arranged Along High-Context and Low-Context Dimension}

From Figure 1 we can see the three Asian countries, Japan, China and Korea fall into the category of high-context cultures in which, according to the Halls, people are very homogeneous with regard to experiences, information networks, and the like. High-context cultures, because of tradition and history, change very little over time. These are cultures in which consistent messages have produced consistent responses to the environment. "As a result", the Halls say, "for most normal transactions in daily life they do not require, nor do they expect, much in-depth, background information" [8]. Meaning, therefore, is not necessarily contained in words. In high-context cultures, information is provided through gestures, the use of space, and even silence. Meaning is also conveyed "through status (age, sex, education, family background, title, and affiliations) and through an individual's informal friends and associates" [9].

Figure 1 also shows that some Western countries fall into the group of low-context cultures in which the population is less homogenous and therefore tends to compartmentalize interpersonal contacts. The Halls explain that this lack of a large pool of common experiences means that "each time they interact with others they need detailed background information" [10]. In low-context cultures, the verbal message contains most of the information and very little is embedded in the context or the participants.

This explanation helps to understand a host of different manifestations of the Eastern and Western communication styles. For instance, the Asian mode of communication is often said to be indirect and implicit, but the Asians can understand each other quite well probably because they share more background information or more context. On the other hand, Western communication tends to be direct and explicit - that is, everything needs to be stated, quite possibly because they are unaware of their surroundings and their environment and have to rely on verbal communication as their main information channel. 
These differences between high-context and low-context cultures are most likely to influence communication. For example, the Westerners who are members of low-context cultures expect messages to be detailed, clear-cut, and definite. If there are not enough data, or if the point being made is not apparent, Westerners will ask blunt, even curt, questions. They feel uncomfortable with the vagueness and ambiguity often associated with limited data. On the other hand, as the Halls say, "High-context people are apt to become impatient and irritated when low-context people insist on giving them information they don't need" [11].

Another problem is that the Easterners who are members of high-context cultures perceive low-context people, who rely primarily on verbal messages for information, as less credible. The Easterners believe that silence often sends a better message than words, and anyone who needs words does not have the information. As the Indonesian proverb states, "Empty cans clatter the loudest."

Differences in this communication dimension can even alter how conflict is perceived and responded to. As Ting-Toomey has observed, the communication differences between high-context and low-context cultures are also apparent in the manner in which each approaches conflict. For instance, because high-context cultures tend to be less open, they hold that conflict is damaging to most communication encounters. For them, Ting-Toomey says, "Conflict should be dealt with discreetly and subtly" [12].

Harris and Moran summarize this dimension as follows: "Unless global leaders are aware of the subtle differences, communication misunderstanding between low- and high-context communicators can result. Japanese communicate by not stating things directly, while Americans usually do the opposite - 'spell it out.' The former is looking for meaning and understanding in what is not said - in the nonverbal communication or body language, in the silences and pauses, in relationships and empathy. The latter places emphasis on sending and receiving accurate messages directly, usually by being articulate with words" [13]. Whether we are global leaders or common global villagers, the study of high- and low-context cultural patterns offers us some insight into what people in diverse cultures pay attention to and what they ignore. Knowing these differences will certainly enhance mutual understanding of the low- and high-context communicators.

\section{Individualism Versus Collectivism}

The single most important value orientation in the west, especially in the United States, is individualism. Broadly speaking, individualism refers to the doctrine, spelled out in detail by the seventeenth-century English philosopher John Locke, that each individual is unique, special, completely different from all other individuals, and "the basic unit of nature" [14].

As is the case with most other cultural patterns or orientations, the origin of this value has had a long history. Two hundred years before Christ, the Latin poet Quintus Ennius offered the following advice that clearly spelled out the independent nature of the individual: "Do not expect strangers to do for you what you can do for yourself." Centuries later, Benjamin Franklin wrote "God helps those who help themselves." Indeed, individualism manifests itself in many Western sayings: "A man's home is his castle." "Pull yourself up by your own boot straps." "Do your own thing." "The squeaky wheel gets the grease." So strong is this notion of individualism in the West, particularly in the United States, that some Westerners believe that there is something wrong with someone who fails to demonstrate individualism.

Goleman highlights some of the characteristics of the culture that values individualism: "People's personal goals take priority over their allegiance to groups like the family or the employer. The loyalty of individualists to a given group is very weak; they feel they belong to many groups and are apt to change their membership if it suits them, switching churches, for example, or leaving one employer for another" [15].

In Western culture which tends toward individualism, an "I" consciousness prevails: competition rather than cooperation is encouraged; personal goals take precedence over group goals; people tend not to be emotionally dependent on organizations and institutions; and every individual has the right to his or her private property, thoughts, and opinions. This culture stresses individual initiative and achievement, and they value direct explicit communication and individual decision making. 
Collectivism, on the other hand, is characterized by a social framework that distinguishes between in-groups and out-groups. People count on their in-group (families, relatives, clans, affiliations) to look after them, and in exchange for that they believe they owe loyalty to the group. Triandis gives us a summary of this situation: "Collectivism means greater emphasis on (a) the views, needs, and goals of the in-group rather than oneself; (b) social norms and duty defined by the in-group rather than behavior to get pleasure; (c) beliefs shared with the in-group rather than beliefs that distinguish self from in-group; and (d) great readiness to cooperate with in-group members" [16].

Collective behavior, like so many other aspects of culture, has deep historical roots in Asia. More than 2500 years ago, Confucius (B.C. 551 - 479 ), the great Chinese thinker, educator, statesman and the founder of Confucianism once said, "If one wants to establish himself, he should help others to establish themselves at first" [17]. In the Chinese literature, it is not difficult to find sayings, proverbs and idioms which denote the value of collectivism: “独木不成林” duти bu cheng lin (one tree does not make a forest / one person alone cannot accomplish much), “众人拾 柴火焰高” zhongren shi chai huoyan gao (A lot of people who collect wood make a fire burning continuously.), “三个臭皮匠, 合成一个诸葛亮” san ge choupijiang, hecheng yige Zhuge Liang (Three cobblers with their wits combined equal Zhuge Liang. / The wisdom of the masses exceeds that of the wisest individual.). And in Korea, there is a proverb Bagjijangdo matdeulmyon natsda (Literally, even a piece of paper weighs lighter if two people carry it. / Many hands make light work.).

In the Eastern culture that values collectivism, a "we" consciousness prevails: identity is based on the social system; the individual is emotionally dependent on families, institutions and affiliations; and individuals trust group decisions. It is generally believed that "Asians tend to be more aware of the connections they have as members of their social groups, and therefore, they tend to be more conscious of the consequences of their actions on their members of their groups" [18]. And in communication behavior, the Easterners are likely to show traits such as indirectness, explicitness, saving face, concern for others, group cooperation, group decision-making, etc.

Strongly influenced by its own cultural orientations, when thrust into a situation that demands a decision, for instance, each group is apt to make false assumptions about members of the other group. Asians will possibly overestimate a Westerner's concern about his group's response to an issue, while a Westerner is likely to assume a greater degree of independence on the part of an Asian with whom he or she is negotiating. This point is clearly made by Foster: "At the negotiating table, differences in this dimension can clearly cause serious conflict. Individual responsibility for making decisions is easy in individualistic cultures; in group oriented cultures this can be different. Americans too often expect their Japanese counterparts to make decisions right at the negotiating table, and the Japanese are constantly surprised to find individual members of the American team promoting their own positions, decisions, and ideas, sometimes openly contradicting one another" [19].

Although we speak of individualism as the underlying value possessed by the Westerners and collectivism as an outstanding value orientation manifested by the Easterners, they are not separate entities, that is, individualism is not peculiar to the West, nor the collectivism to the East. As a matter of fact, all people and cultures have both individual and collective dispositions.

\section{Equality Versus Hierarchy}

Closely related to individualism is the Western value of equality, which is emphasized in everything from government (everyone has the right to vote ) to social relationships ("Just call me by my first name"). As Scollon \& Scollon point out, "There were two political revolutions which arose out of Enlightenment philosophy: the French Revolution and the American Revolution... The motto of the French revolution liberté, egalité, fraternité captures the essence of the concept of the person. As it was essential for the Enlightenment and the utilitarian concept of society for each individual to make free choices, it was also essential for each member to be considered an equal. The greatest happiness could not be achieved for the greatest number if some members of society were allowed to have a somewhat larger portion of happiness than others. The American 
constitution also established the legal basis for social equality, though two hundred years later the details of this social equality remain to be worked out in practice" [20].

In the West the value of equality is prevalent in both primary and secondary social relationships: for example, most of the primary social relationships within a family tend to advance equality rather than hierarchy. Formality is not important, and children are often treated as adults and can call their parents by their given names. Kinship is far from being felt as a significant tie among members of society. In many cases, kinship relationships are seen as significant barriers to individual self-realization and progress.

In secondary relationships, we find that most friendships and co-workers are also treated as equals. Subordinates consider superiors to be the same kind of people as they are, and superiors perceive their subordinates the same way. People in power, be they supervisors or government officials, often interact with their constituents and try to look less powerful than they really are. The powerful and the powerless try to live in concert.

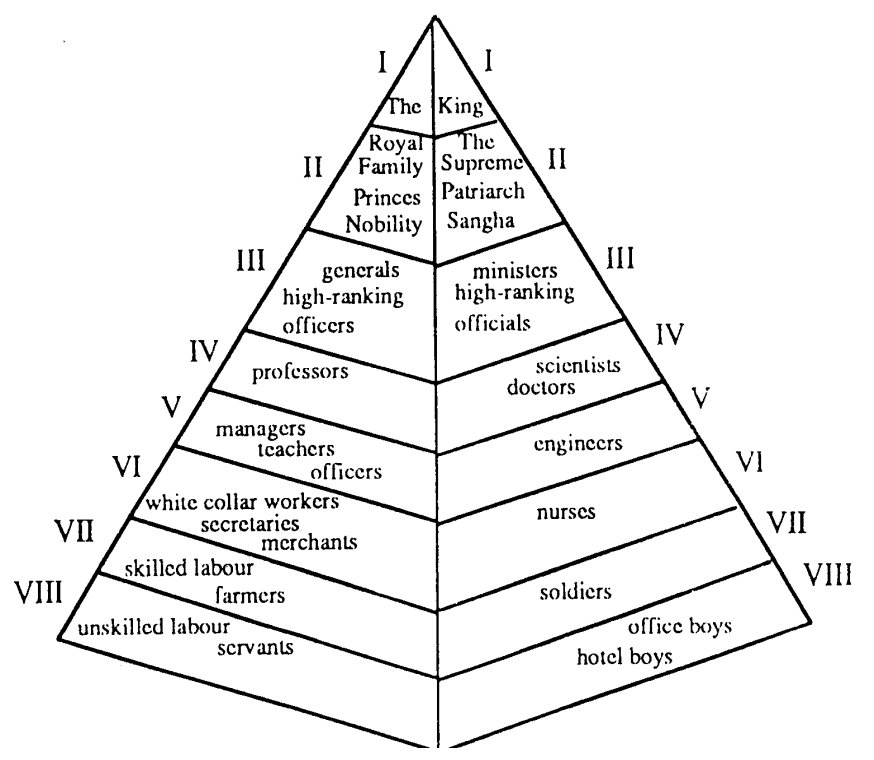

Figure 2. The Hierarchy of Thai Society

However, it has been said by some ethnographers that all relationships in Asia are hierarchical. Figure 2 depicts the pyramid structure of social hierarchy of Thailand [21]. The value of hierarchy is clearly manifested in a Confucian saying, “君君, 臣臣, 父父, 子子” junjun, chenchen, fufu, zizi (King is king; subject is subject; father is father, and son is son), that is, everyone should behave according to his social status. This notion of hierarchy has been so strong in Asia that even today most Asians are quite conscious in any interaction who is older and who is younger, who has a higher level of education and who has a lower level, who is in a higher institutional or economic position and who is lower, or who is teacher and who is student. They are especially conscious of such relationships within extended family structures, with each person carefully placed with a kinship term which tells all participants to which generation they belong in relation to others. In an extended Chinese family, for instance, a small child, after learning how to call papa and mama, has to know how to call 爷爷 yeye (grandpa), 奶奶 nainai (grannie), 大伯 dabai (uncle), 大娘 daniang (aunt) 叔叔 shushu (uncle), 婶婶 shenshen (aunt), 姑姑 gugu (aunt), 姑夫 gufu (uncle), 舅 舅 jiujiu (uncle), 舅妈, jiuma (aunt), 姨姨 yiyi (aunt), 姨夫 yifu (uncle), 哥哥 gege (elder brother), 嫂子 saozi (sister in law), 姐姐 jiejie (elder sister), 姐夫 jiefu (brother in law), and so on.

In Asia, as in any other societies in which such traditional kinship relationships are emphasized, any individual is acutely aware of his or her obligations and responsibilities to those who have come before as well as to those who come after. From birth one is made conscious of the debt owed to one's own parents, which is largely carried out in the form of duty and obedience. As 
one grows up, he is also made acutely conscious of the debt owed to one's own children and other descendants, which is largely carried out through nurture, responsibility, and benevolence.

Although in the fervor of the so-called Great Cultural Revolution in China (1966 - 1976) children were encouraged to criticize their parents at home, students were inspired to criticize their teachers in schools, and people were urged to criticize Confucius in the whole society, "they failed to remove the soil in which Chinese family had been planted," [22] and there are still strong Confucian influences throughout the Chinese culture.

In secondary relationships of this culture, we can observe signs of social hierarchy in nearly every setting. In schools, children seldom interrupt the teacher, show great reverence and respect for authority, and ask very few questions. In organizations, you find a greater centralization of power, a large proportion of supervisory personnel. People believe that power and authority are facts of life and everybody has a rightful place in the society. So wherever you go and whatever you do, you are to behave according to the status which you perceive you have in the hierarchy of the society.

This difference in equality and hierarchy will most likely play out in the choice of strategies of interpersonal politeness, with the Westerner using strategies of involvement (i.e., to pay attention to others, show a strong interest in their affairs, point out common in-group membership or points of view with them, or use first names) as a way of emphasizing equality, and the Asians using strategies of independence (i.e., to make minimal assumptions about the needs or interests of others, not to "put words into their mouths", to give others the widest range of options, or use more formal names and titles) as a way of showing deference [23].

In the field of business, problems may also arise because of different cultural values in equality and hierarchy between East and West. In Taiwan, Hong Kong and the private companies of mainland China, there is a tendency for business to be small, family-owned and controlled structures, which operate very much along traditional lines more closely associated with kinship than Western corporate structures. Western companies emphasize finding "the right person" for each job, i.e., selecting individual employees on the basis of their training and experience, while their Eastern counterparts may think it important to employ their in-group members or certain persons who are well placed in the local structure, even where they may not have the initial training and experience.

\section{Assertiveness Versus Interpersonal Harmony}

The American culture is also known for its assertive and aggressive communication behavior. This type of behavior is clearly depicted in an essay entitled "The American Uncivil Wars", which recently appeared in U.S. News \& World Report:

"It is a time schools use metal detector to keep out guns and knives, when universities insist on speech and behavior codes to stem the tide of hatred and disrespect, when legal cases become shouting matches, when the Internet is lettered with raunch and menace, when political campaigns resemble food fights, when trash talk and head butts are the idiom of sports, and when popular culture tops itself from week to week with displays of violence, sex, foul language and puerile confession" [24].

These signs of assertive and aggressive behavior did not develop by chance. Studies of American family life have shown that parents encourage, approve, and reward aggressive behavior [25]. As American culture values individualism, equality, competition and freedom of speech, assertiveness is bound to be encouraged. This idea is reinforced by Wenzhong and Grove:

"In a culture where individualism is as highly valued as it is in the United States, people are expected to take the initiative in advancing their personal interests and well-being and to be direct and assertive in interacting with others. High social and geographic mobility and the comparatively superficial nature of many personal attachments create a climate where interpersonal competition and modest level of abrasiveness are tolerated and even expected." [26].

One can easily imagine that communication problems may arise when cultures which value assertiveness come in contact with cultures that value accord and harmony. The example given by Cooper and Cooper is a case in point. In an international conference, members of the Israeli delegation, who were arguing their position in a dynamic manner, complained that the 
representatives from Thailand showed no interest in or enthusiasm for the meeting; they were "just sitting there." The Thai delegates, on the other hand, thought the professors from Israel were angry because they were "using loud voices." Both responses were, of course, a product of cultural experiences. "The Thai learn how to avoid aggression rather than how to defend themselves against it." And members of the Jewish culture stress what they believe to be healthy disagreement [27].

The Japanese also place a high value on interpersonal harmony. As Moeran puts it, "Self is subordinated in the interests of harmony" [28]. Like many other dimensions of culture, interpersonal harmony can be found in the deep structure of Japanese society. As Hendry notes, "The value attached to harmony in Japan dates back to at least the Seventeen-Article Constitution of Prince Shotoku (594 - 622), which esteemed concord above all things as the subject of the first article and the underlying theme of all the others" [29]. The Japanese cultural thinking that emphases harmony is obviously shown in the ways of doing business. Perhaps exaggerating slightly, Harris and Moran assume that harmony is "more important in business dealings for the Japanese than achieving higher sales and profits" [30].

Like the Thai and Japanese, the Chinese welcome harmony, as Chen and Xiao state: "It is without a doubt that harmony is one of the primordial values of Confucianism and of the Chinese culture" [31]. This principle also has a long and meaningful history in China. Its roots are in the Chinese religion: "According to Confucianism, the ultimate goal of human behavior is to achieve 'harmony' which leads Chinese people to pursue a conflict-free and group-oriented system of human 'relationships'" [32]. Because harmony is a guiding principle for the Chinese, they will not tolerate outward displays of anger" [33]. Two Chinese proverbs speak to the issue of outward signs of anger: "The first man to raise his voice loses the argument" and "One hurtful word wounds like a sharp sword."

\section{Conclusion}

Because of different history, geography, ideology, economics, politics, culture, language, life style, social customs, etc., people in different parts of the world, especially those in the East and those in the West do differ profoundly in their cultural patterns or orientations.

For instance, the Westerners are assumed to be members of low-context cultures, and need direct and explicit verbal messages because they share little background information or context. And they have strong orientations to value individualism, equality and assertiveness in their social interaction and interpersonal communication. The Easterners, on the other hand, are believed to be high-context, and do not require much in-depth background information since most of the information is already in the individuals. And they, due to their history and tradition, tend to respect collectivism, hierarchy and interpersonal harmony in the society. These underlying cultural differences may be problematic in intercultural communication if we are in lack of this knowledge.

We are living in an age when changes in technology, travel, economic and political systems, immigration patterns, and population density have created a world in which we increasingly interact with people from different cultures. And whether we like it or not, those interactions will continue to grow in both frequency and intensity. In the $21^{\text {st }}$ century, the world has grown so small that we all depend on each other now. What happens in one place of the world affects other places. Therefore, it is to the advantage of all the nearly 6 billion of us who share the planet to improve our interpersonal and intercultural communication abilities.

All in all, our beliefs, values, or cultural patterns and orientations determine what we perceive, how we react to situations, and how we relate to other people. Understanding the basis or deep structures of the cultural differences may help people to see beneath the surface to find out why people from other cultures act as they do. In other words, knowing the differences in cultural patterns or orientations is far more important that just knowing whether people eat with chopsticks or knives and forks. This discovery may lead us to appreciate the rich diversity and genius that exist both in the western and eastern hemispheres of the globe. In the end, it is only by understanding others that we might be able to gain insight into ourselves and our own culture. And as the Halls put it, "An understanding of different cultures may well be our own most important asset in meeting the challenges of our times, both abroad and at home." 


\section{References}

[1] Kroeber, A. L., \& Kluckhohn, C., 1952. "Culture: A Critical Review of Concepts and Definitions," Harvard University Peabody Museum of American Archaeology and Ethnology Papers, 47, p. 181.

[2] Bates, D. G., \& Plog, F., 1976. Cultural Anthropology, $3^{\text {rd }}$ Ed., New York: McGraw-Hill, 6.

[3] Samovar, L. A., Porter, R. E., \& Stefani, L. A., 2000. Communication Between Cultures, Beijing: Foreign Language Teaching and Research Press/Brooks/Cole/Thomson Learning Asia, p. 58.

[4] Rokeach, M., 1973. The Nature of Human Values, New York: Free Press, p. 161.

[5] Hall, E. T., 1976. Beyond Culture, Garden City, NY: Doubleday, p. 74.

[6] Hall, E. T., \& Hall, M. R., 1990. Understanding Cultural Differences: German, French and Americans, Yarmouth, ME: Intercultural Press, p. 6.

[7] Hall, 1976, p. 79.

[8] Hall \& Hall, 1990.

[9] Foster, 1992, p. 280.

[10] Hall \& Hall, 1990, p. 7.

[11] Hall \& Hall, 1990, p. 9.

[12] Ting-Toomey, S., 1997. "Managing Intercultural Conflicts Effectively," in Intercultural Communication: A Reader, $8^{\text {th }}$ Ed., Samovar, L.A., \& Porter, R. E. (Eds.), Belmont, CA: Wadsworth, p. 394.

[13] Harris \& Moran, 1996, p. 25.

[14] Stewart, E. C., \& Bennett, M. J., 1991. American Cultural Patterns: A Cross-Cultural Perspective, Yarmouth, ME: Intercultural Press, p. 133.

[15] Goleman, D., 22 December 1990. "The Group and Self: New Focus on a Cultural Rift," New York Times, p. 40.

[16] Triandis, H. C., 1990. "Cross-Cultural Studies of Individualism and Collectivism," in CrossCultural Perspectives, Berman, J. J. (Eds.), Lincoln: University of Nebraska Press, p. 52.

[17] Samovar, Porter \& Stefani, 2000, p. 68.

[18] Scollon, R., \& Scollon, S. W., 2000. Intercultural Communication: A Discourse Approach, Beijing: Foreign Language Teaching and Research Press/Blackwell Publishers Ltd., p. 133.

[19] Foster, D. A., 1992. Bargaining Across Borders, New York: McGraw-Hill, p. 267.

[20] Scollon \& Scollon, 2000, p. 114.

[21] Kummer, M., 1992. "Politeness in Thai" in Trends in Linguistics - Studies and Monographs 59, Watts, R. J., et al. (Eds.), Mouton de Gruyter/Berlin/New York, p. 330.

[22] Chu, G. C., \& Ju, Y., 1993. The Great Wall in Ruins: Communication and Culture Change in China, Albany, NY: State University of New York Press, p. 79.

[23] Scollon \& Scollon, 2000. 37, p. 131.

[24] U.S. News \& World Report, 22 April, 1996, pp. 66 - 67.

[25] Moghaddam, F. M., Taylor, D. M., \& Wright, S. C., 1993. Social Psychology in CrossCultural Perspective, New York: W. H. Freeman, p. 125.

[26] Wenzhong, H., \& Grove, C. L., 1990. Encountering the Chinese: A Guide to Americans, Yarmouth, ME: Intercultural Press, p. 23

[27] Cooper, R., \& Cooper, N., 1994. Culture Shock: Thailand, Portland, OR: Graphic Arts Center Publishing Company, p. 86.

[28] Moeran, B., 1968, "Individual, Group and Seishin: Japan's Internal cultural Debate," in Japanese Culture and Behavior, rev. ed., Lebra, T. S., \& Lebra, W. P. (Eds.), Honolulu: University of Hawaii Press, p. 75.

[29] Hendry, J., 1987. Understanding Japanese Society, New York: Routledge, p. 194.

[30] Harris, P. R. \& Moran, R. T., 1979. Managing Cultural Differences, Houston, TX: Gulf, p. 296.

[31] Chen, G., \& Xiao, X., 1993. The Impact of Harmony on Chinese Negotiations (paper presented at the Annual Convention of the Speech Communication Association, Miami Beach, FL), p. 4. 
[32] Chen, G., November 1993. A Chinese Perspective of Communication Competence (paper presented at the Annual Convention of the Speech Communication Association, Miami Beach, FL), p. 6.

[33] Wenzhong \& Grove, 1990, p. 65. 